\section{Thonic bandage: bridging a gap for self-bandaging and homecare}

\section{Pierre Gonon}

CEO Thonic Innovation, Monistrol sur Loire, France

The Science of Bandaging is well documented. Hysteresis and Stretchability are technical specifications which are easily measured in laboratories and allow practitioners to anticipate the effects the bandages will have on a patient's limb. The recent development of simple devices has opened a new field of investigation with the possibility to measure the sub-bandage pressures and quantify the Static Stiffness Index (SSI).

This increasing knowledge and understanding of bandages characteristics has allowed the development of numerous guidelines for the management of conditions such as lymphoedema and Venous Leg Ulcers (VLUs) and they all come to the same conclusion that compression bandages must be applied by trained staff. ${ }^{1}$ The authors of the European Dermatology Forum's Guideline for Diagnostics and Treatment of VLUs ${ }^{2}$ who reviewed studies using a whole range of different bandaging systems even noticed that It made no difference which bandage was used provided it was correctly applied. This is a confirmation of what many practitioners feel, i.e. bandaging is not only a science but also an art. It also means that if all available bandaging systems can be efficient, the fundamental question every prescriber should ask themselves when prescribing a bandage is Who is going to apply the bandage I am prescribing?

When the staff in specialist care centers have the skills and the time to apply compression bandages correctly, this question takes a whole new dimension when it comes to what is happening in primary care where self-bandaging is promoted or, more importantly, when the bandages are applied usually by primary care nurses at the patients' homes.

The argument of primary care nurses applying bandages and reaching much lower VLUs healing rates at 6 months when compared to specialist centers $(45 \%$ vs $70 \%)^{3,4}$ can probably be brought down to 2 main issues: guidelines and training.

The publication and regular update of guidelines for the management of VLUs does not seem to be sufficient to ensure standard and quality care to patients. ${ }^{5}$ This can probably be partly explained by the perceived contradictions between recommendations from different guidelines, ${ }^{6}$ such as the need for daily skin care in the management of lymphoedema ${ }^{1,7}$ vs the effective oedema reduction achieved with bandages applied for 4 days. ${ }^{1}$

Training programs allow primary care nurses to really improve their bandaging skills but the challenge seems to be the maintenance of these skills over time: nurses who had improved their bandaging skills with training went back to their initial level after 6 to 10 weeks. ${ }^{8}$ The workload these primary care nurses have to face can probably explain this. Although non disease nor treatment specific, a survey conducted in
Correspondence: Pierre Gonon, CEO Thonic Innovation, 43120 Monistrol sur Loire, France.

E-mail: pierre.gonon@thonic.care

This work is licensed under a Creative Commons Attribution 4.0 License (by-nc 4.0).

(c) Copyright P. Gonon, 2017

Licensee PAGEPress, Italy

Veins and Lymphatics 2017; 6:6628

doi:10.4081/vl.2017.6628

2013 among district and community nurses in the $\mathrm{UK}^{9}$ showed that $81 \%$ of them had

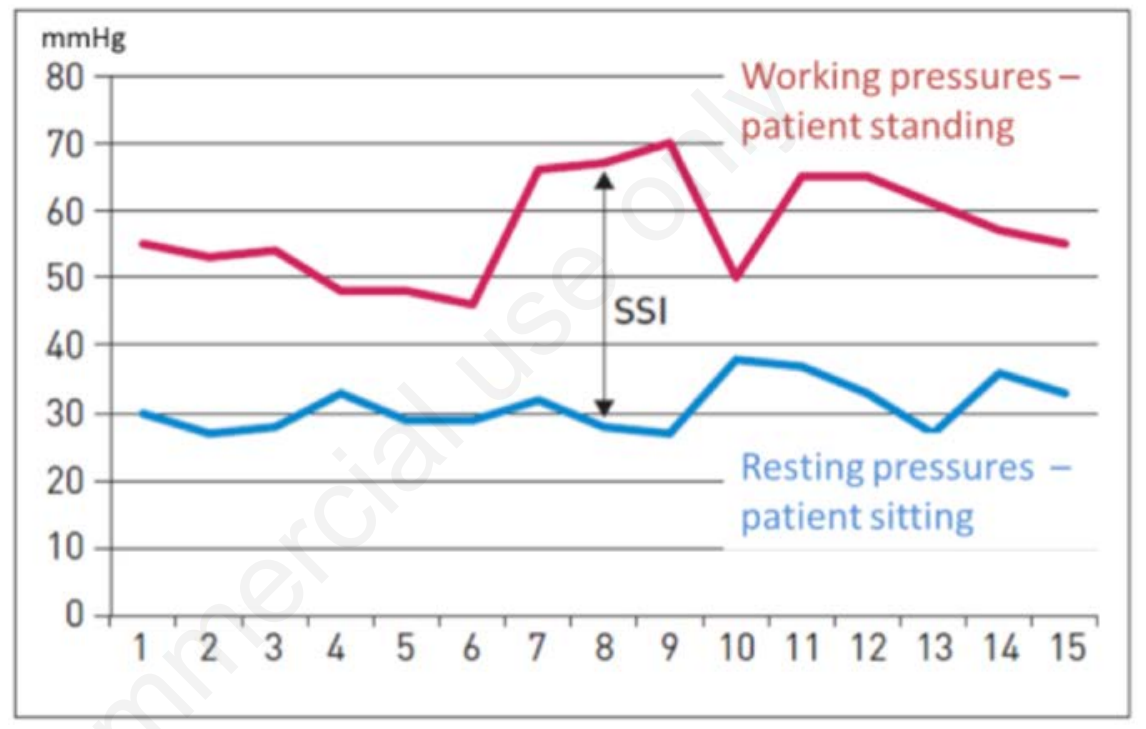

Figure 1. Thonic bandage Static Stiffness Index - Interface resting/working pressures measured with Picopress on 5 healthy volunteers (Courtesy by Dr J.P. Begnini and Dr J.F. Uhl).

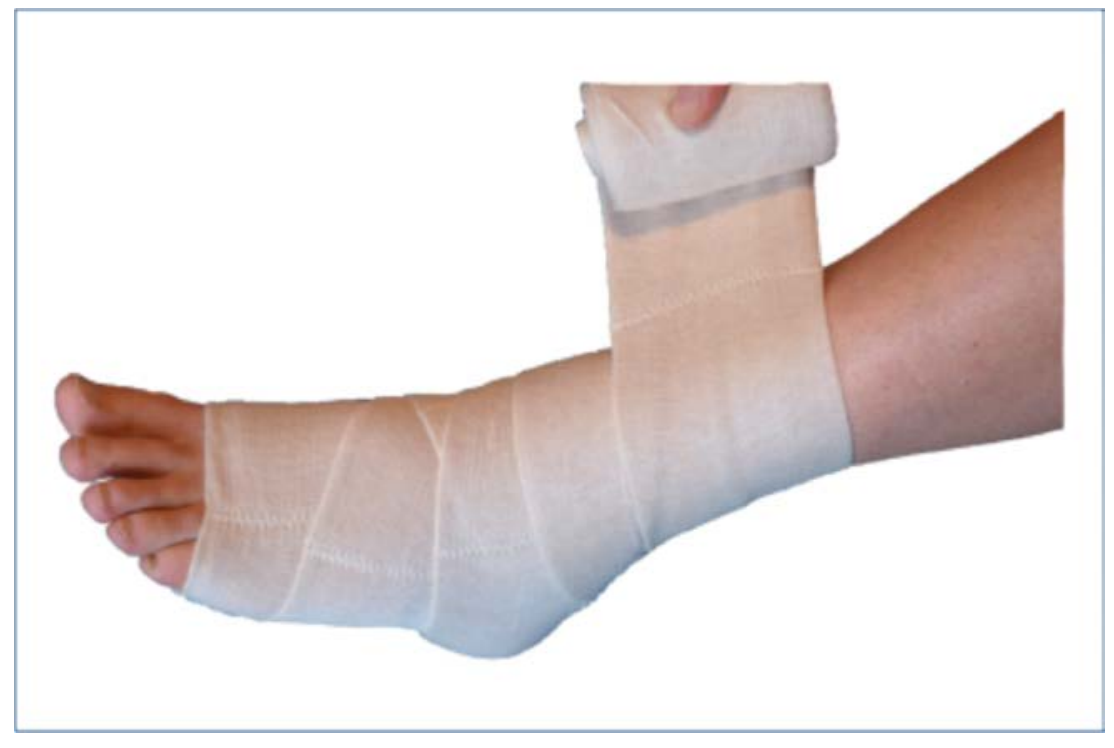

Figure 2. Application of Thonic bandage on lower limb. 
worked an average of 80 minutes extra-time per 7-9 hour shift, with $75 \%$ reporting they had left necessary activities undone.

This overload of work on primary care nurses, which seems to be common in many countries, cannot be ignored and leads to the need of simpler and safer bandaging systems that can also be applied for selfbandaging. The evolution in practice from multi-layer bandaging systems to simpler 2 layer systems in the recent years is clearly a sign of this need.

Thonic bandage's simple design, which combines innovatively the fundamentals of compression therapy (inelastic and elastic materials; Figure 1), allows the simultaneous application of both components (Figure 2) which not only reduces the application time but makes it also easier to apply. Not having to worry about which bandage goes against the patient's skin might sound trivial but it will make a major difference for patients, untrained practitioners, and trained practitioners under heavy workloads. With Thonic bandage, they don't even have to worry about which side goes against the skin as they are both $100 \%$ cotton, and therefore extremely comfortable. Thonic bandage technical design also allows a safer application as the stretchability of the elas- tic material is mechanically limited, thus reducing the risks of patients or untrained professionals applying dangerously high pressures by over stretching it. Finally, Thonic bandage is washable and reusable which makes it extremely cost-efficient and eco-friendly. Thonic bandage is therefore the solution to bridge the gap between specialist care and homecare bandaging, including self-bandaging.

\section{References}

1. International Lymphoedema Framework. Position document. Best practice for the management of lymphoedema; 2nd Edition. Available from: http://www.woundsinternational.com/m edia/issues/210/files/content_175.pdf

2. Neumann $M$, Cornu-Thénard A, Jünger $\mathrm{M}$, et al. Evidence based (S3) Guidelines for diagnostic and treatment of venous leg ulcers. JEADV 2016;30:1843-75.

3. Brown A, Bums E, Chalmers L, et al. Effect of a national community intervention programme on healing rates of chronic leg ulcer: randomised con- trolled trial. Phlebology 2002;17:47-53.

4. Cullum N. Nelson EA, Flemming K, Sheldon T. Systematic reviews of wound care management: (5) beds; (6) compression; (7) laser therapy, therapeutic ultrasound, electrotherapy and electromagnetic therapy. Health Technol Assess 2001;5:1-221.

5. Franks PJ, Barker J. Management of patients with venous leg ulcers: challenges and current best practice. Wounds Austr EWMA J 2016;16:1.

6. Scott IA, Glasziou PP. Improving the effectiveness of clinical medicine: the need for better science. Med J Austr 2012;196:304-8.

7. Lymphoedema Framework. Best practice for the management of lymphoedema. International consensus. London: MEP Ltd.; 2006.

8. Feben K. How effective is training in compression bandaging techniques? $\mathrm{Br}$ J Community Nurs 2003;8:80-4.

9. Ball J, Philippou J, Pike G, Sethi J. Survey of district and community nurses in 2013 - Report to the Royal College of Nursing. London: NNRU, King's College London - Employment Research Ltd.; 2013. 